\title{
PENGARUH RASIONALISASI TERHADAP RELASI INTERPERSONAL
}

\author{
Jonidius Illu \\ Sekolah Tinggi Teologi Injili Arastamar (SETIA) Jakarta
}

\begin{abstract}
Abstrak
Kejatuhan manusia dalam dosa mengakibatkan rusaknya gambar dan rupa Allah dalam diri manusia kehidupannya telah dikotori oleh dosa sehingga akibatnya manusia memiliki natur dosa dan bertindak berdasarkan kehendak yang sudah tercemar yang memberi dampak yang negatif. Salah satunya adalah manusia tidak mau disalahkan dan cendrung memakai defense mechanism (pertahanan diri) untuk mempertahankan eksistensinya. Sistem pertahanan diri adalah suatu sikap pertahanan diri yang terjadi karena ia id terlalu tinggi dan superoge tinggi, maka yang terjadi adalah orang tersebut memiliki sistem pertahanan diri. Manufer pertahanan diri biasanya sudah mulai nampak sejak usia dini atau masa kanak-kanak. Ketika mengalami ancaman, konflik dan frustrasi yang merupakan bagian dari pertumbuhan, secara otomatis pertahanan dirinya muncul sebenarnya jika pertahanan diri dapat dioleh dengan baik maka dapat menolong untuk keluar dari rasa sakit akibat kegelisahan, konflik, hanya saja kebanyakan dari kita tidak dapat bertahan dengan baik karena tidak berusaha dengan maksimal.
\end{abstract}

Kata kunci: rasionalisasi, relasi, interpersonal

\section{Pendahuluan}

Manusia adalah suatu pribadi yang berharga yang telah diciptakan menurut gambar dan rupa Allah yang melebihi semua ciptaan lainnya karena diberikan akal budi untuk berpikir, memiliki emosi dan kemauan untuk melaksanakan segala sesuatu dengan penuh tanggung jawab. ${ }^{1}$

Menurut Zick dan Elton ${ }^{2}$ defense mechanism mempunyai dua (2) macam karakteristik yaitu:

a) Penyangkalan atau perubahan realita, yaitu tidak siap menghadapi kenyataan hidup yang sebenarnya atau mau menolak kenyataan yang sedang terjadi;

b) Melakukan sesuatu yang tidak disadari (unconscious), yaitu sikap yang dilakukan untuk menekan akan apa yang sedang terjadi, tetapi ia tidak tahu akan kondisinya yang sebenarnya yang sedang terjadi dengan dirinya. Hal ini juga ditegaskan oleh Lester Sdorow,

"The ego may resort to defense mechanisms, which distort reality, to protect itself from the anxiety cause by id impulses, particularly those of sex and aggression. The ego may also use defense mechanism to relieve theanxiety caused by unpleasant personal experiences and unacceptable personal characteristics. Each of us uses defense mechanism to varying extents, which contributes to the distinctiveness of each of our personalities. But, defense mechanism also prevent the individual from recognizing and dealing with the true source of his or her anxiety. ${ }^{3}$

\footnotetext{
${ }^{1}$ Tim Penyusun, Berteologi Abad XXI, (Jakarta: Perkantas, 2015), 216.

${ }^{2}$ Zick Rubin dan Elton B. Mc. Neil, Psychology Being Human, (New York: Harper and Row Publisher, 1981).

${ }^{3}$ Lester Sdorow, Psychology, (Dubuque: Wm. C. Brown Publishers, 1990), 440.
} 
Jika demikian, bagaimana pandangan Kristen terhadap sistem pertahanan diri. Menurut Julianto sistem pertahanan diri ada baiknya pada saat itu, namun perlu dievaluasi karena sering kita tidak jujur. Ia mengemukakan beberapa pendapat tentang sistem pertahanan diri ${ }^{4}$, yaitu

a) Sistem pertahanan diri itu biasanya unconscious. Kita tidak menyadari bahwa kita sedang membela diri kita sendiri, tetapi Tuhan melihat dan mengerti hati kita sampai sedalam-dalamnya. Kalau Tuhan menyadarkan kita, maka kita harus memperbaiki.

b) Jika sistem pertahanan diri ini dipakai untuk mengelabui dan menipu diri sendiri tentu saja ini dosa, sehingga orang Kristen yang matang mengambil waktu untuk menganalisa sikap dan tingkah laku (evaluasi dan instropeksi).

c) Sistem pertahanan diri bertujuan untuk mempertahankan harga diri yang palsu dan menghindarkan diri dari kecemasan. Mengapa orang Kristen punya banyak topeng. Kita selalu ingin tampil saleh dan rendah hati.

d) Semua orang memakai sistem pertahanan diri karena ini adalah untuk memberikan reaksi terhadap frustrasi dan konflik serta diapaki untuk menutupi kelemahan kita.

e) Sistem pertahanan diri ini membuat kita jika melihat orang membuat hal yang sama dengan apa yang kita lakukan kita malah tidak suka, karena itu sering mengingatkan kita tentang kelemahan kita dan kita sering tidak suka pada orang tersebut.

f) Dalam hati kita yang terdalam, kita sadar bahwa kita selfish (egois) dan ada kecendrungan merusak atau persepsi kita terhadap orang lain distorted (menyimpang). Kita sering buta terhadap kekurangan kita.

\section{Pembahasan}

\section{A. Latar Belakang Masalah}

Who am i? Pertanyaan ini menarik bagi penulis karena diarahkan kepada pribadi, tentang siapa diri kita sebenarnya. Bagi penulis, pertayaan ini menunjukkan pada: 1 . Penerimaan kita akan siapa kita sebenarnya; 2. Sudah tampak atau apa yang tampak dalam diri kita; 3. Apa yang orang lain harapkan dari tindakan kita; 4. Masa lalu kita mengenai apa yang terjadi dan dialami; 5. Bagaimana seharusnya atau idealnya kita dalam bertindak.

Dari beberapa pertanyaan di atas, maka apa yang sebenarnya terjadi dengan diri yang mengakibatkan terjadi sistem pertahanan diri, misalnya:

a) Seseorang sejak usia dini tidak diperlakukan dengan baik atau tidak menerima kasih sayang yang cukup dari orangtua. ${ }^{5}$ Hal ini mengakibatkan ia menjadi pribadi yang bertumbuh haus kasih sayang dan pada umumnya ia akan membentuk sistem pertahanan diri.

b) Apa yang berkaiatan dengan defense mechanism, seseorang diperlakukan dengan sikap yang tidak baik sehingga bisa mengalami beberapa keadaan yang sering membuat tidak teratur dalam berbagai hal, antara lain:

- $\quad$ Sering berpikir sendiri atau tenggelam dalam pikiranya sendiri dengan masalah yang dihadapinya, ia tidak mau mengutaran apa yang dialaminya kepada orang lain.

- $\quad$ Mudah depresi. Dengan situasi yang dialaminya dan berulangkali bisa mengakibatkan ia depresi.

\footnotetext{
${ }^{4}$ Julianto Simanjuntak, Perlengkapan Seorang Konselor, (Jakarta: Layanan Konseling Keluarga dan Karir, (LK3), 2007, 130-131.

${ }^{5}$ Tim Penyusun, Buku Pegangan Konselor: Kasus, catatan, dan kegiatan untuk individu Jilid I, (Jakarta: YAPKI, 2008), 80-81.
} 
- Mudah terpengaruh dengan lingkungan, misalnya terlibat dalam perkelahian.

- $\quad$ Selalu berpikir yang buruk terhadap orang lain.

\section{B. Rasionalisasi}

\section{Pengertian rasionalisasi}

Sebagian dari cara individu mereduksi perasaan tertekan. Kecemasan, stress atau pun konflik adalah dengan dilakukan sistem pertahanan diri, baik yang ia lakukan secara sadar (conscious) dan secara tidak sadar (unconscious). Hal ini ditegaskan juga dalam Wikipedia bahwa," This process can be in a range from fully conscious (e.g. to present an external defense against ridicule from others) to mostly subconscious (e.g. to create a block against internal feelings of guilt) ${ }^{6}$." Hal ini sesuai pendapat yang dikemukakan oleh Sigmun Freud sebagai berikut: "such defense mechanism are put into operatin whenever anxiety signal a danger that the original unacceptable impulses may reemerge. ${ }^{7}$

Menurut Wikipedia In psychology, rationalization is the process of constructing a logical justification for a flawed decision, action or lack thereof that was originally arrived at through a different mental process. ${ }^{8}$

Freud menggunakan istilah sistem pertahanan diri untuk menunjukkan proses tak sadar yang melindungi si individu dari kecemasan melalui pemutarbalikan kenyataan. Pada dasarnya strategi-strategi ini tidak mengubah kondisi objektif bahaya dan hanya mengubah cara individu mempersepsi diri atau memikirkan masalah itu. Jadi mekanisme pertahanan diri melibatkan (defense mechanism) unsur penipuan diri. Hal ini ditegaskan lagi oleh Freud bahwa, "over-determined," one reasonable aspect is likely to be discoverable ${ }^{9}$."

Istilah mekanisme bukan merupakan istilah yang paling tepat karena menyangkut peralatan mekanik. Istilah tersebut mungkin karena Sigmund Freud banyak dipengaruhi oleh kecendrungan abad ke-19 yang memandang manusia sebagai mesin yang rumit. Sebenarnya yang dibicarakan dalam strategi yang dipelajri individu untuk meminimalkan kecemasan dalam situasi yang tidak dapat mereka tanggulangi secara efektif, tetapi karena mekanisme pertahanan diri masih merupakan istilah terapan yang paling umum maka istilah ini masih akan tetap digunakan. ${ }^{10}$

Beberapa bentuk sistem pertahanan diri yang dikemukakan oleh Sigmund Freud yaitu represi, proyeksi, pemindahan obyek, pembentukan reaksi, sublimasi implus dan rasionalisasi. ${ }^{11} \mathrm{Hal}$ ini juga ditegaskan oleh James W. Kalat bahwa, "when people attempt to prove that they action are rational and justifiable and thus worthy approval, they are using rationalization 12." Dan dikemukakan dalam Wikipedia bahwa, "In psychology, rationalization is the process of constructing a logical justification for a flawed decision, action or lack thereof that was originally arrived at through a different mental process. ${ }^{13}$ Contoh-contohnya antara lain:

${ }^{6}$ Wikipedia, The Free Encyclopedia. Htm.

${ }^{7}$ John L. Vogel, Thinking About Psychology, (Chicago: Helson-Hall, 1985), 401.

${ }^{8}$ Wikipedia, The Free Encyclopedia. Htm.

${ }^{9}$ Gardner Murphy, Personality, (New York and London: Haper and Brothers Publisher, 1947), 547.

${ }^{10}$ Sigmund Freud, Suatu Pengantar ke dalam Ilmu Jiwa, (Jakarta: Pembangunan, 1954), 108.

${ }^{11}$ B. R. hergenhann and Mattew H. Olson, An Introduction to Theories of Personality, (Amerika: Prentice Hall and Upper Saddle River), 37-38.

${ }^{12}$ James W. Kalat, Introduction to psychology, (California: Wadsworth Publishing Company, 1990, 475.

${ }^{13}$ Rasionalization (psychology) - Wikipedia, 28 August 2007. 
a) Seorang pelajar yang lebih memilih menonton daripada belajar mengatakan, "banyak belajar tidak membuat saya pintar."

b) Seseorang yang terlambat mengumpulkan tugas akhirnya mengatakan, "saya tidak benar-benar menginginkan pekerjaan ini lagi."

c) Seorang pegawai yang terlambat ke kantor mengatakan saya tidak datang tepat waktu karena apakah saya efektif bekerja jika saya dating pada waktu yang sudah ditentukan.

Jadi rasionalisasi sering dimaksudkan sebagai usaha individu untuk mencari-cari alasan yang dapat diterima secara sosial untuk membenarkan atau menyembunyikan perilakunya yang buruk. Rasionalisasi juga muncul ketika individu menipu dirinya sendiri dengan berpura-pura menganggap yang buruk adalah baik atau yang baik adalah yang buruk. Atau dengan kata lain rasionalisasi adalah pembenaran tingkah laku melalui argument yang seolah-olah benar untuk menutupi sikapnya yang tidak dapat diterima oleh orang lain dengan cara merasionalisasikan (membuatnya nampak masuk akal).

\section{Faktor-faktor yang mempengaruhi timbulnya rasionalisasi}

Dua faktor umum yang mempengaruhi timbulnya rasionalisasi, yaitu:

\section{a. Rasa rendah diri}

Rasa rendah diri yaitu perasaan minder atau merasa tidak mampu untuk melakukan sesuatu tanpa bantuan orang lain dan melihat orang lain memiliki kemampuan yang lebih dari dirinya sendiri.

Yakub Susabda ${ }^{14}$ menjelaskan rasa rendah diri adalah keadaan emosi yang dialami orang oleh karena berbagai sebab, yang mengakibatkan munculnya berbagai perasaan yang negatif seperti kegelisahan, tidak aman (insecure), tidak mampu (inadequacy), takut gagal. Menurut Yakub Susabda, inferiority disebabkan karena

- Realita inferiority non-primer (kenyataan inferiority dalam hal-hal yang tidak primer), yaitu ada pada semua orang oleh karena memang tidak pernah ada orang yang sempurna dan tidak semua kebutuhan manusia itu dirasakan primer oleh setiap orang. ${ }^{15}$

- Realita inferior primer, yaitu menyangkat hal-hal yang dirasakan primer, maka pengaruhnya bisa serius dalam kehidupan yang bersangkutan.

- $\quad$ Poor self-image (pengenalan yang buruk terhadap dirinya sendiri), yaitu banyak orang yang sebenarnya sangat capable tetapi tidak berhasil dalam banyak hal, dan sebabnya seringkali bukan oleh karena mereka tidak mampu tetapi oleh karena poor self-image. Mereka selalu cendrung melihat dan memperlakukan dirinya sendiri secara inferior, hal ini cendrung terjadi karena: (a) sikap lingkungan yang cendrung selalu mengecilkan dirinya; (b) sikap lingkungan yang menuntut lebih dari kemampuan.

- Kegagalan berkali-kali, yaitu oleh karena pengalaman hidupnya yang diwarnai dengan banyak kegagalan. Sering kali proses kehidupan tidak selancar yang manusia kehendaki, kadang-kadang kegagalan datang bertubitubi.

\footnotetext{
${ }^{14}$ Yakub Susabda, Pastoral Konseling Jilid 2, (Malang: Gandum Mas, 2003), 48.

${ }^{15}$ Kurangnya percaya diri bukanlah atribut yang dibawa sejak lahir, tetapi lebih merupakan sesuatu yang didapat (acquired) setelah bertahun-tahun dibesarkan dalam sistem keluarga tertentu. Kita semua rentan terhadap berbagai variabel dan pengaruh di sekitar kita. Tim Penyusun, Buku Pegangan Konselor: Kasus, catatan, dan kegiatan untuk individu Jilid II, (Jakarta: YAPKI, 2008), 115.
} 


\section{b. Iri hati}

Adalah perasaan tidak rela orang lain mendapatkan penghargaan, pujian, nilai baik, respon yang baik. Perasaan tidak senang oleh karena sesuatu yang dimiliki oleh orang lain, ada perasaan kehilangan atau kekurangan sesuatu yang ada pada orang lain, melihat orang lain memiliki sesuatu yang tidak ia miliki, membuat ia merasa kehilangan, tetapi tidak selalu bahwa ia ingin memiliki sesuatu itu. ${ }^{16}$ Kecenderungan untuk membandingkan diri dengan orang lain (I don't possess "the Good", the other person/the rival possess "the Good"). Jadi, apa yang kita pikirkan tentang "perbandingan" inilah yang membuat kita envy (bukan sesuatu/ "the Good" itu). Envious tidak selalu pada orang yang lebih tinggi. Envious juga bisa terhadap orang yang lebih rendah, lebih miskin, lebih lemah, lebih bodoh, dan lebih tidak mampu dari diri sendiri. Jadi iri hati adalah sikap:

- $\quad$ Blindness/kebutaan, yaitu tidak mampu untuk melihat sesuatu yang positif di dalam diri sendiri.

- $\quad$ A negation of awareness (denial, cancellation, tidak ada awareness) dan unconscious wish untuk menghancurkan apa yang positif dalam diri orang lain dan dalam diri kita sendiri juga (misalnya tetangga punya mobil baru, maka dia menyumpah "semoga kalo dipakai mobilnya ketabrak). Membandingkan orang lain dengan diri sendiri, rasa iri, (misalnya aku dapat nilai B, dia dapat A). Iri hati adalah suatu keadaan emosi dalam diri seseorang yang seringkali disembunyikan (tidak mau diakui/diingat-ingat) dan muncul pada saat-saat tertentu, misalnya melihat teman-teman yang dapat perlakuan khusus, mendapat penghargaan dan melihat adanya tidak fair.

Salah satu contoh dalam Alkitab, yaitu cerita Lukas 15:11-32 perumpamaan tentang anak yang hilang, yaitu anak sulung tidak rela melihat adiknya kembali dan diterima dengan baik oleh bapanya, merasa adik itu tidak layak menerima kebaikan bapanya, dan merasa dirinya lebih layak untuk dikasihi dan diperlakukan special karena dia bekerja keras dan patuh pada ayahnya.

Nature dari iri hati adalah dosa, iri hati bisa terjadi pada individu siapa saja, meskipun dengan latar belakang (pendidikan, lingkungan) yang baik sekalipun, dan iri hati bisa dimanifestasikan dalam bentuk apa saja (depresi, agresif , contoh: menjelekjelekan orang lain), hostile, pembunuhan , dan dendam.

Beberapa contoh lain dalam Alkitab antara lain:

- 1 Samuel 18:7-9, Saul benci kepada Daud dan sangat ingin membunuh Daud.

- Kejadian 4:3-6, Kain mempersembahkan korban persembah, Habel juga mempersembahkan korban persembahan, namun Kain iri hati persembahan Habel yang diterima Allah.

- $\quad$ Yunus. Yunus marah karena Allah mengasihi orang Niniwe yang bertobat dan berbalik kepada Allah. Yunus merasa bahwa orang Niniwe pantas dimusnahkan dan dapat malapetaka dari Tuhan, dan Yunus lebih senang melihat mereka mati daripada bertobat.

Akibat dari iri hati yaitu cenderung merusak. Amsal 14:30, "Hati yang tenang menyegarkan tubuh, tetapi iri hati membusukkan tulang."

Nature dari envy yaitu biasanya muncul bersama-sama dengan yang lain (misalnya: Low self esteem, inferiority, defense mechanism-tidak pernah independent).

${ }^{16}$ Susabda, Pastoral Konseling, 24-25. 
Yakobus 3:16, "sebab di mana ada iri hati, di situ ada kekacauan dan segala macam perbuatan jahat". Iri hati tidak dapat dihindari namun dapat dihambat perkembangannya dengan cara mengembangkan diri atau menemukan potensi dalam diri dan dengan tekun mengembangkan diri.

Berikut ini beberapa penyebab iri hati:

- $\quad$ Sikap orang tua yang treat/memperlakukan anak-anak dengan tidak sama (contoh: perlakuan orangtua yang berbeda antara adik dan kakak atau pilih kasih atau membanding-bandingkan).

- Rejection of love/rusaknya rasa kasih sayang (contoh: anak mau menyenangkan orangtuanya dengan memberi sesuatu pada orangtuanya tetapi tidak diterima dengan baik, maka anak akan merasa tidak berarti atau tidak berguna).

- $\quad$ Distorted thinking (cenderung berfikir negatif), contoh: jika anak tidak diperlakukan begini, ia beranggapan mungkin bapak/ibu tidak sayang lagi). Dasar dari suatu hubungan yang benar adalah penerimaan, apabila anak telah membangun "secure" terhadap orangtuanya, maka anak akan mengembangkan membangun attachment-attachment yang lain (multi Attachment) dengan orang lain. pad akhirnya di waktu dewasa anak ini akan membangun relationship yang sehat terhadap sesamanya.

- Our Own problems with self-esteem, yaitu lack of self-worth, Feeling of inferiority, asumsi bahwa self-worth bisa didapat melalui possession of something Good atau achievements. Jika 'the good' atau achievements menjadi menjadi milik oran lain, maka kita mengalami envy (kita mengharapkan orang lain tidak mempunyai achievement itu (sehingga selfworth kita terganggu).

- $\quad$ Kecenderungan untuk tidak memperhitungkan, tidak mampu melihat hal-hal positif dalam diri (an unconscious dismissal of the goodness, truth and beauty in oneself and in others).

\section{Relasi Interpersonal}

\section{Pengertian relasi interpersonal}

Walter Winchell berpendapat bahwa, "tanpa teman-teman, kehidupan bukanlah kehidupan sebenarnya. Kesepian akan membuat pertumbuhan pribadi seolah berhenti dan membuat kehidupan tanpa arti, serta akan berakhir dengan kegagalan berlanjut. Selain itu, akan mengembangkan kecemasan, depresi, serta membaut seorang menjadi sangatrentah terhadap tekanan, kehilangan masa lalu dan akhirnya merasa kehilangan hakikat kemanusiaannya, bahkan bisa mematikan."

Kesepian adalah perasaan terkecil, penuh kesedihan, kerena merasa diri hanya hidup seorang diri. Keadaan ini tentu saja terasa sangat menyakitkan. Kesepian bisa disebabkan perasaan terisolasi dan perasaan tidak bergabung dalam satu kelompok pergaulan tertentu di mana kita bisa berbagi dalam hal minat, kesusahan, perhatian dan member perasasaan berada dalam suatu komunitas tertentu. Perasaan berada dalam komunitas tertentu akan menghindarkabn kita untuk merasa terisolasi secara emosional kerana tidak memiliki relasi yang mendalam seperti halnya relasi pada pasangan kekasih, pasangan perkawinan, orangtua dan anak-anak, yang memberi penghayatan ikatan emosi yang erat. Terisolasi secara fisik memang tidak akan membuahkan rasa kesepian, namun berada dalam lingkup pergaulan juga belum tentu membuat kita merasa tidak kesepian. Sebenarnya terpenuhinya kebutuhan pertemanan dan kebutuhan dukungan sosial yang membuat kita tidak merasa sendiri walaupun di 
saat tertentu kita bisa saja secara fisik memang harus sendiri. Jadi, tidak tidak terjalin relasi yang intim serta terjalinnya hubungan yang memuaskanlah yang menjadi penyebab utama kita merasa kesepian serta mengalami keadaan yang membauat kita merasa tidak bahagia dan nyaman.

Menurut Johnson, relasi interpersonal bukanlah sesuatu hal yang mewah untuk dapat kita raih. Kita dapat belajar menggapai orang lain untuk menjalin relasi interpersonal, mengapa? Kerana relasi interpersonal merupakan kunci perkembangan dan pertumbuhan personal, identitas, produktivitas, sukses dalam karier, perasaan berareti, memiliki kehidupan yang berkualitaws, sehat fisik dan mental, kemampuan aktualisasi diri, serta kemampuan mengatasi tekanan hidup dan tentu saja mendapatkan hakikat kemanusian. ${ }^{17}$

Hal ini juga dikemukanan dalam www.abacon.com/commstudies/interpersonal bahwa, "One way of defining interpersonal communication is to compare it to other forms of communication. In so doing, we would examine how many people are involved, how physically close they are to one another, how many sensory channels are used, and the feedback provided. Interpersonal communication differs from other forms of communication in that there are few participants involved, the interactants are in close physical proximity to each other, there are many sensory channels used, and feedback is immediate. An important point to note about the contextual definition is that it does not take into account the relationship between the interactants." 18

Jadi manusia sebagai makhluk social perlu berinteraksi satu dengan yang lain untuk membagi perasaan satu dengan yang lain agar ada ketenangan atau doronghan yang didapatkan dari orang lain.

\section{Hal-hal penting yang perlu diperhatikan dalam relasi interpersonal}

\section{a. Adaptasi}

Mengapa manusia ingin berelasi dengan orang lain? Dan mengapa membutuhkan adaptasi? Manusia sebagi pribadi yang dapat bersosialisasi dengan manusia lain sehingga perlu beradaptasi terhadap lingkungan dimana ia berelasi. Tujuan dari adaptasi adalah supaya ia bisa diterima oleh lingkungan dimana ia berelasi dan dapat membangun komunikasi yang baik dengan orang-orang disekitarnya sehingga ia tidak merasakan dirinya sebagai pribadi yang mengisolir diri dalam lingkungan tersebut. Contohnya ketika penulis di terima di STT Setia Jakarta maka penulis harus berelasi dengan orang-orang di STT Setia Jakarta dan menyesuaikan diri dengan lingkungan tersebut sehingga pekerjaan dan pelayanan yang penulis ikuti dapat berjalan dengan baik dan merasa nyaman dalam lingkungan tersebut karena sudah mengetahui orangorang sekitar melalui relasi yang baik.

b. Interaksi

Identitas kita terbina dan terbangun dari relasi kita dengan orang lain, karena selagi kita berinteraksi dengan orang lain, kita memperhatikan respon mereka terhadap kita, kita cari umpan balik melalui bagaimana mereka mengamati diri kita dan bagaimana kita belajar memandang diri kita sendiri seperti halnya mereka mamandang kita. Melalui refleksi dari orang lainlah kita mengembangkan gambaran yang jelas dan cermat tentang diri kita sendiri. Contohnya: bila orang lain memandang diri kita sebagai orang yang baik, maka kita harus cendrung melihat diri kita sesuai dengan pandanagan mereka. Kita jga mencoba menjadikan kekaguman kita tentang karekter orang lain,

\footnotetext{
${ }^{17}$ Johnson, 1991.

${ }^{18}$ www.abacon.com/commstudies/interpersonal. html.
} 
PENGARUH RASIONALISASI TERHADAP RELASI INTERPERSONAL (Jonidius Illu)

menjadi bagian dari diri kita. Dalam relasi dengan lingkungan, kita harus mengadopsi aturan social yang menyertai posisi kita, apakah dalam peran sebagai mahasiswa, dosen, atau jemaat atau posisi lainnya. Hanya dalam interaksi dengan orang lainlah, kita akan menemukan siapa sebenarnya identitas diri pribadi kita.

\section{Pengaruh Rasionalisasi Terhadap Relasi Interpersonal}

Pengaruh dari rasionalisasi dalam hubungan dengan orang lain (relasi interpersonal) meliputi:

1. Adanya sikap hati-hati terhadap orang-orang yang ada di sekitar ketika bersosialisasi, karena takut mereka akan mengetahui kekurangan yang ada dalam diri.

2. Memiliki pola pikir yang sering berbeda dengan orang-orang yang disekitar, misalnya ketika berdiskusi tentang suatu topik, berbeda pendapat dengan mereka.

3. Berpikir bahwa akan lebih nyaman ketika sendirian dari pada berelasi dengan orang lain.

\section{KESIMPULAN}

Dari penjelasan di atas penulis memberikan kesimpulan sebagai berikut:

1. Masa lalu dengan berbagai kondisi yang dihadapi dapat membentuk siapakah kita sekarang.

2. Sadar bahwa keluarga sebagai lembaga yang sangat penting untuk membentuk suatu pribadi.

3. Rasionalisasi sebagai bentuk penyangkalan diri untuk membenarkan diri dan cendrung ke arah yang berlawanan dengan orang lain sebab telah memiliki pendapat sendiri tentang sesuatu.

4. Akan cendrung takut dan rendah diri karena apa yang dipikirkan tidak tercapai dengan baik sehingga lebih memilih untuk tidak berelasi dengan orang lain.

5. Beradaptasi dan berinterasi dengan orang lain penting untuk membentuk suatu hubungan yang sehat. 


\section{Referensi}

Collin's, Gary R., Christian Counseling, Melbourne: Word Publishing, 1988

Freud, Sigmund, Suatu Pengantar ke dalam IImu Jiwa, Jakarta: Pembangunan, 1954.

Hergenhann, B. R. and Mattew H. Olson, An Introduction to Theories of Personality, Amerika: Prentice Hall and Upper Saddle River, 1990.

Hiltnes, Seward, Constructive Aspects of Anxiety, New York: Abingdon Press, 1963.

Kalat, James W. Introduction to psychology, California: Wadsworth Publishing Company, Menninger, W. Walter, Copyng with Anxiety, London: Jason Aronson, 1996.

Murphy, Gardner Personality, New York and London: Haper and Brothers Publisher, 1947.

Rubin, Zick dan Elton B. Mc. Neil, Psychology Being Human, New York: Harper and Row Publisher, 1981.

Sdorow, Lester Psychology, Dubuque: Wm. C. Brown Publishers, 1990.

Simanjuntak, Julianto Perlengkapan Seorang Konselor, Tangerang: Layanan Konseling Keluarga dan Karir, (LK3), 2007.

Susabda, Yakub, Pastoral Konseling Jilid 2, Malang: Gandum Mas, 2003.

Vogel, John L. Thinking About Psychology, Chicago: Helson-Hall, 1985.

Tim Penyusun, Buku Pegangan Konselor: Kasus, catatan, dan kegiatan untuk individu Jilid I, (Jakarta: YAPKI, 2008).

Tim Penyusun, Berteologi Abad XXI, (Jakarta: Perkantas, 2015).

Paul Enns, Buku Pegangan Teologi, (Malang: SAAT, 2003).

Anxiety - Wikipedia, The Free Encyclopedia. html.

www.abacon.com/commstudies/interpersonal. html.

Article, The National Institute of Mental Health, USA: Gov, November 6, 2007.

Rasionalization (psychology) - Wikipedia, 28 August 2007

Wikipedia, The Free Encyclopedia. html. 